\title{
ANALYZING RADIOCARBON RESERVOIR OFFSETS THROUGH STABLE NITROGEN ISOTOPES AND BAYESIAN MODELING: A CASE STUDY USING PAIRED HUMAN AND FAUNAL REMAINS FROM THE CIS-BAIKAL REGION, SIBERIA
}

\author{
Christopher Bronk Ramsey ${ }^{1}$ Rick Schulting ${ }^{1}$ Olga I Goriunova ${ }^{2}$ Vladimir I Bazaliiskii ${ }^{\bullet}$ \\ Andrzej W Weber ${ }^{3}$
}

\begin{abstract}
Dietary offsets in radiocarbon dates are becoming increasingly interesting to researchers, not only because of their impact on the reliability of chronologies but also because of the possibilities for extracting further dietary information from the ${ }^{14} \mathrm{C}$ data itself. This is the case with the cemeteries of the Cis-Baikal region being studied as part of the international Baikal-Hokkaido Archaeology Project set up to examine hunter-gatherer cultural dynamics in eastern Asia. Fortunately, to control for a freshwater reservoir offset, we were able to obtain a number of paired terrestrial herbivore and human material for ${ }^{14} \mathrm{C}$ dating. This article tests the correspondence between stable isotope evidence and the offsets seen in ${ }^{14} \mathrm{C}$ values and the implications for the analysis of the ${ }^{14} \mathrm{C}$ measurements as "chronometric dates." This is an unusually well-documented example of freshwater reservoir offsets, providing an ideal case study to test different approaches to analyzing such offset information. Here, a purely Bayesian approach is compared with the more frequently applied linear regression analysis.
\end{abstract}

\section{INTRODUCTION}

The calibration of radiocarbon dates relies on having reliable information about the ${ }^{14} \mathrm{C}$ measurements expected for samples of known age. For samples that get their carbon directly from the atmosphere, this is exactly what the atmospheric calibration curve provides. When the carbon in an organism comes from a different source, this is more problematic. For the oceans, a marine calibration curve gives an overall surface ocean average estimate (depleted in ${ }^{14} \mathrm{C}$ by about $5 \%$, or $400 \mathrm{yr}$ ), and deviations from this average are known for some regions in some time periods (primarily preindustrial, late-Holocene values, Stuiver and Braziunas 1998). For other reservoirs of carbon, such as lakes and rivers, the information is rather sparse and may have to be directly assessed as part of any dating study for which it is relevant.

There is a further level of complexity added when dealing with organisms, most notably humans, who draw their carbon from a number of different sources as a result of a mixed diet. However, the variations in diet are themselves interesting and provide extra information, which can help to disentangle the effects of the different reservoirs on the ${ }^{14} \mathrm{C}$ content of samples.

Offsets in ${ }^{14} \mathrm{C}$ dates due to dietary inputs are very important in some regions, where a dietary component from either marine (e.g. Dewar and Pfeiffer 2010; Naito et al. 2010; Ascough et al. 2012) or freshwater (e.g. Lanting and van der Plicht 1998; Cook et al. 2001; Shishlina et al. 2007, 2009, 2012; Olsen et al. 2010; Wood et al. 2013) systems is present. In some cases, these offsets are reasonably well correlated with measurements on stable isotope values or other indicators of the dietary system.

This article looks at a particular example of this type of problem, with which we can demonstrate some different approaches to data analysis. The sites involved in the study (Figure 1) are cemeteries in the Cis-Baikal region (Lokomotiv, Shamanka, Ust'-Ida, Kurma XI, and Khuzhir Nuge XIV) spanning the Neolithic and Early Bronze Age periods. The culture historical models for this region

1. Research Laboratory for Archaeology and the History of Art, Dyson Perrins Building, University of Oxford, South Parks Road, Oxford OX13QY, United Kingdom. Email: christopher.ramsey@rlaha.ox.ac.uk.

2. Department of Archaeology and Ethnography, Irkutsk State University, Karl Marx Street 1, Irkutsk 664003, Russia.

3. Department of Anthropology, 13-15 H.M. Tory Building, University of Alberta, Edmonton, Alberta T6G 2H4, Canada.

Proceedings of the Radiocarbon and Archaeology 7th International Symposium

Ghent, Belgium, April 2013 | Edited by Mark Van Strydonck, Philippe Crombé, and Guy De Mulder

(C) 2014 by the Arizona Board of Regents on behalf of the University of Arizona 


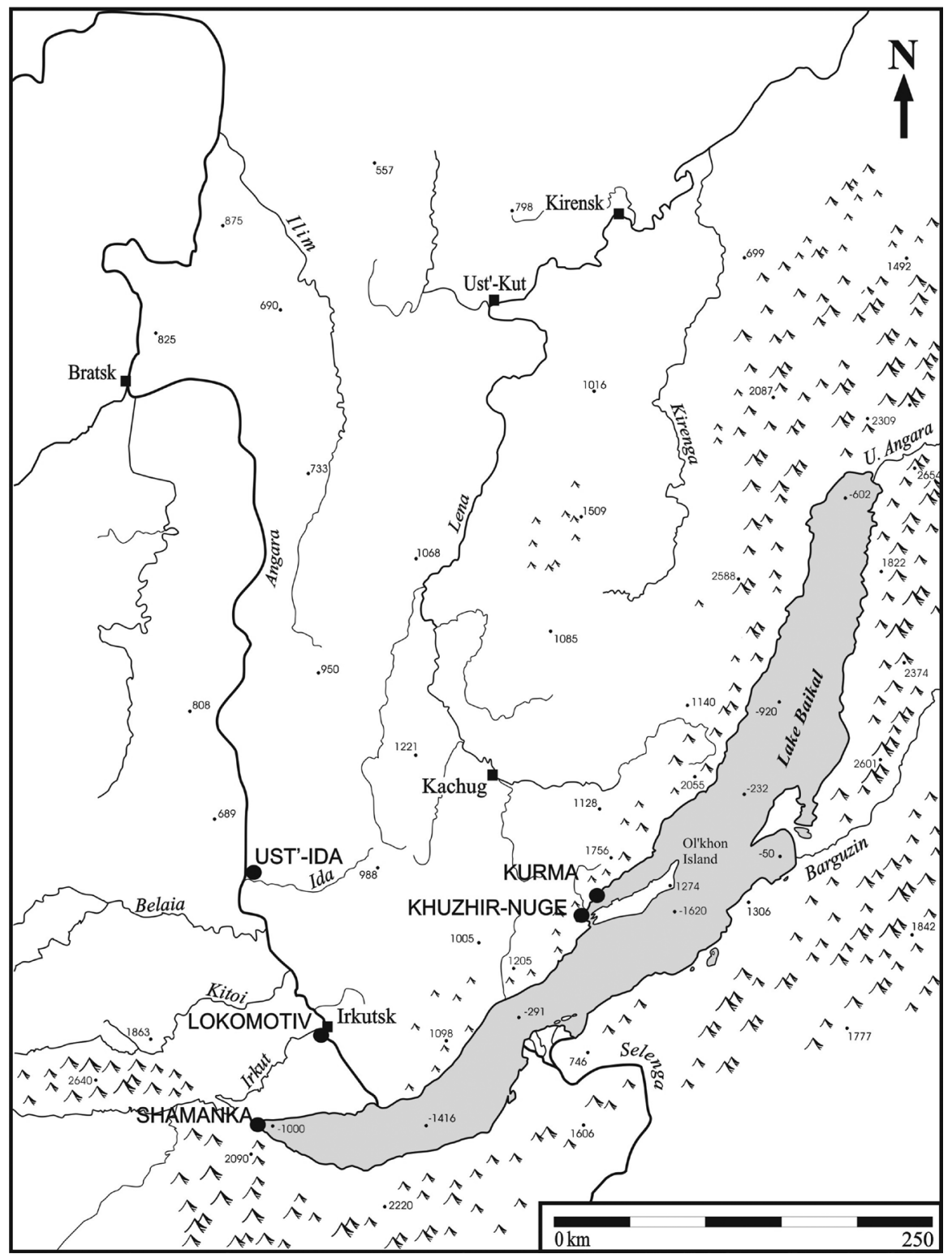

Figure 1 Location of middle Holocene cemeteries within the Cis-Baikal region of Siberia used in the study.

rely heavily on the ${ }^{14} \mathrm{C}$ dating of the human remains (e.g. Mamonova and Sulerzhitskii 1989; Weber 1995; Weber et al. 2005, 2006). There is also very well-documented dietary variability at several levels: temporal, spatial, and individual (Weber and Goriunova 2011; Weber et al. 2011). The isotope ecology of Lake Baikal is unusual for a freshwater lake in having extremely variable $\delta^{13} \mathrm{C}$ values in its primary producers, ranging from -30.5 to $-9.0 \%$ (Kiyashko et al. 1998). This means that $\delta^{13} \mathrm{C}$ alone cannot reliably identify the degree of consumption of foods from the lake. Stable nitrogen isotope $\left(\delta^{15} \mathrm{~N}\right)$ measurements largely reflect trophic level, and, as food chains are nearly always longer in aquatic systems (Minagawa and Wada 1984), they offer a means to investigate 
human use of this resource. Both $\delta^{13} \mathrm{C}$ and $\delta^{15} \mathrm{~N}$ values show that the humans from the region were certainly exploiting aquatic resources, from Lake Baikal itself as well as from the neighboring rivers (Katzenberg and Weber 1999; Weber et al. 2002, 2011; Katzenberg et al. 2009, 2010). However, given the only weak correlation between $\delta^{13} \mathrm{C}$ and ${ }^{14} \mathrm{C}$ offsets in this ecosystem, the focus in this paper is on $\delta^{15} \mathrm{~N}$ measurements.

The contribution of aquatic food inevitably varies between individuals as well as over time, and so we should expect a relationship between the stable isotope values for human bone collagen and the degree of depletion in ${ }^{14} \mathrm{C}$ content in comparison with the atmosphere. This is a situation that is mirrored in many archaeological sites in different regions. The Cis-Baikal cemeteries have an advantage in that the burials frequently have associated with them a rich assemblage of artifacts, including objects made from the bones and teeth of terrestrial herbivores, whose ${ }^{14} \mathrm{C}$ content should directly track that of the atmosphere. Assuming no significant curation of material, this allows us to obtain pairs of dates from burials (on human and herbivore bone/tooth collagen) which, in turn, enable us to measure directly the reservoir offset and thus study the relationship between the stable isotopes and the ${ }^{14} \mathrm{C}$ offset in different ways.

\section{THE RADIOCARBON DATA}

For each of the graves dealt with in this study, we have measurements on human bone and animal teeth. In some instances, the human bone dates have been replicated and are here reported as a combined date (one of which fails a chi-squared test - see comments in Table 1 caption and results discussion). The underlying data are given in the online supplementary table file, and the details of the date combination and stable isotope data compilation are given in Schulting et al. (2014). Table 1 shows the main elements of the data relevant to the discussion here.

The offsets between the human and animal bone values are presented in Figure 2. There is in general a good linear relationship between the offset of the dates and their $\delta^{15} \mathrm{~N}$ values. The two most obvious outliers are data points 9 and 10 and in these specific cases there may be reason to exclude them from the analysis. For data point 9 , the ${ }^{14} \mathrm{C}$ dates on the human bone do not seem to be as reproducible as we would expect and the human burial represented by data point 10 is of an infant aged 2-4, likely still subject to a nursing effect responsible for its anomalously high $\delta^{15} \mathrm{~N}$ value (Waters-Rist et al. 2011).

\section{LINEAR REGRESSION ANALYSIS}

As a first-order approximation, we will assume a linear dependency between the stable isotope values for the humans and the offsets in the ${ }^{14} \mathrm{C}$ dates of the human bones to those of the herbivores. Thus, if the parameters are defined as

$$
\begin{array}{ll}
y_{i} & \text { the offset }\left({ }^{14} \mathrm{C} \mathrm{yr}\right) \text { for the } i \text { th human in our data set } \\
x_{i 1} & \delta^{15} \mathrm{~N} \text { value for the } i \text { th human in our data set } \\
x_{i 2} & \delta^{13} \mathrm{C} \text { value for the } i \text { th human in our data set }
\end{array}
$$

the expected model for the offset is

$$
y_{i}=\beta_{0}+\beta_{1} x_{i 1}+\beta_{2} x_{i 2}+\varepsilon_{i}
$$

where $\varepsilon_{i}$ is a noise or error term specific to the sample, which might occur due to measurement error or due to the reservoir offset varying for reasons not reflected in the stable isotope measurements. We expect the $\varepsilon_{i}$ terms to be normally distributed with a mean of zero. Given that the offsets $y_{i}$ have a measurement uncertainty associated with them, we would expect $\varepsilon_{i}$ to have a standard deviation to 


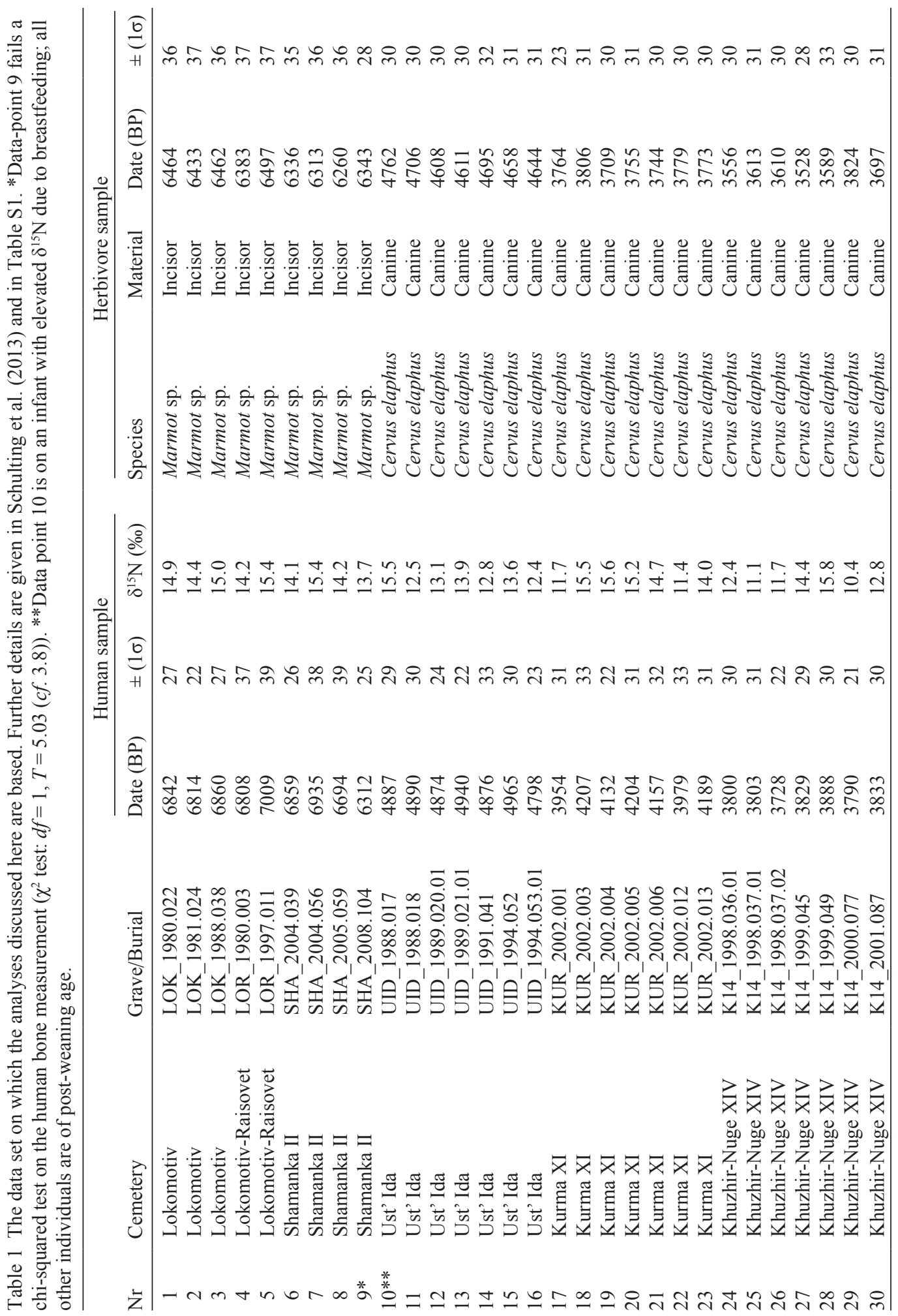


be at least as large as this measurement uncertainty. Furthermore, in practice, we would also expect to see overdispersion because we know that variation in offset is unlikely to have a perfect linear relationship given variation in the end-point stable isotope values for the food sources and other physiological factors independent of diet.

Since in this particular case we have all of the values for each human $\left(y_{i}, x_{i 1}, x_{i 2}\right)$, a simple ANOVA linear regression is all that is required to obtain an estimate for $\beta_{0}, \beta_{1}$, and $\beta_{2}$. The standard deviation of the residuals provides an estimate of the scatter in $\varepsilon_{i}$.

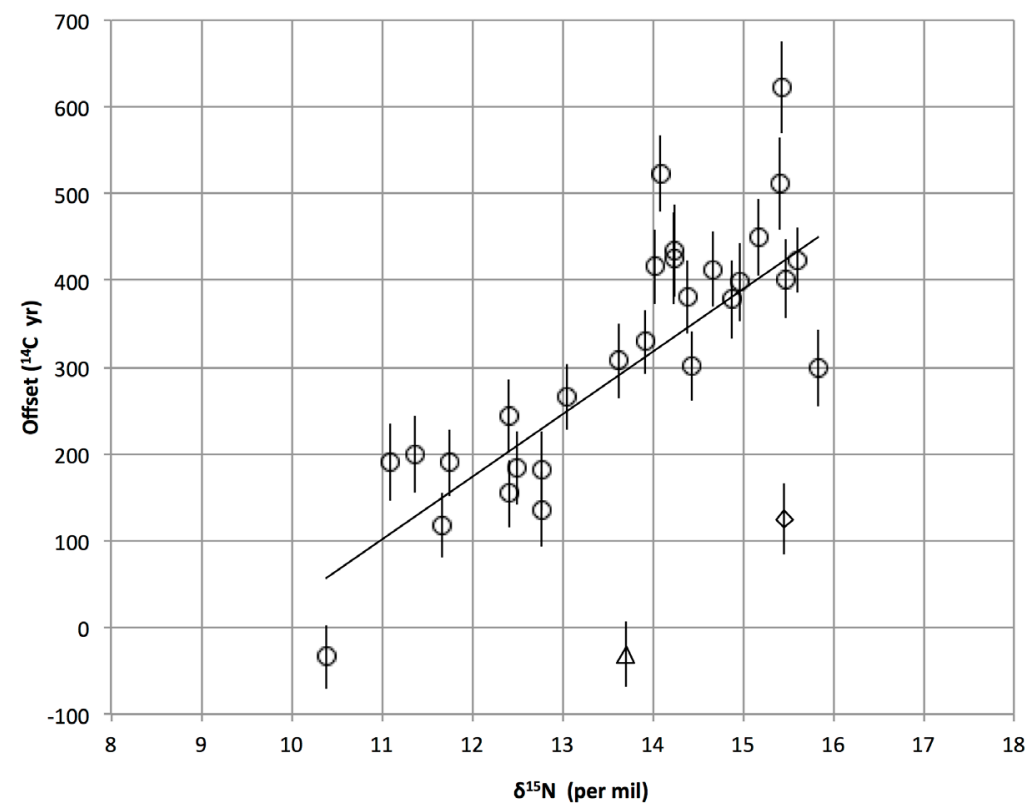

Figure 2 Plot showing the relationship between $\delta^{15} \mathrm{~N}$ and the offset seen between human and animal bones in the Baikal data set. Uncertainty in the offset is shown at $1 \sigma$. The two largest outliers from a clear linear relationship are data point 9 (triangle), where the human dates fail a $\chi^{2}$ test, and data point 10 (diamond), which is from an infant burial.

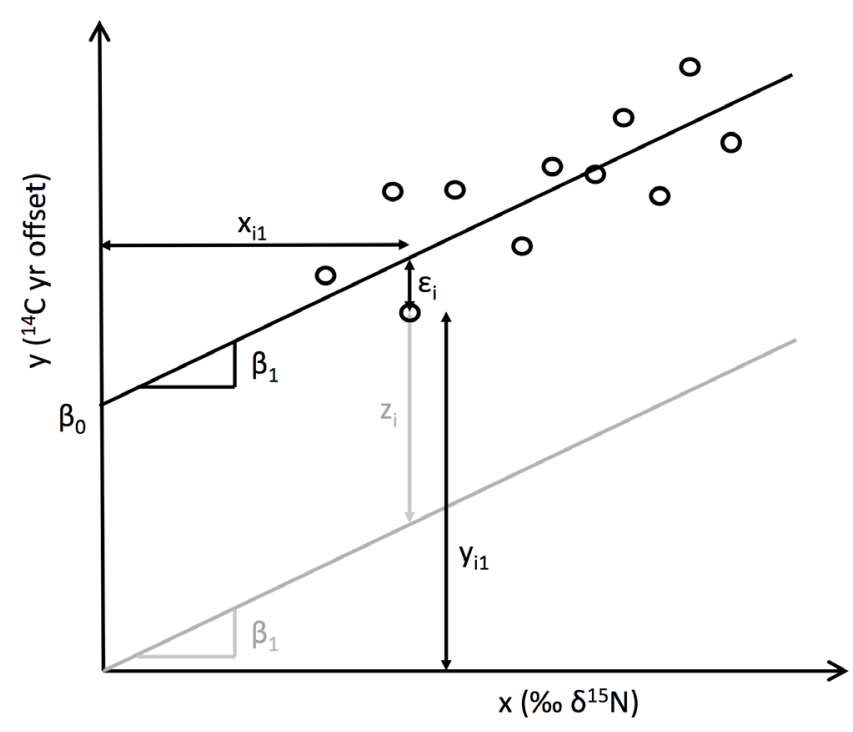

Figure 3 Schematic graph of the models used in the linear regression analysis (black) and Bayesian analysis (gray). For the linear regression analysis the residual errors $\varepsilon_{i}$ are assumed to be drawn from a Normal distribution with a mean of zero. For the Bayesian analysis the parameters $z_{i}$ are modeled to be from a Normal distribution with a mean and standard deviation that are found by the model. 
The application of linear regression to the Cis-Baikal data set is discussed in more detail in Schulting et al. (2014). In practice in this case, as in many others, it turns out that one parameter (the $\delta^{15} \mathrm{~N}$ value, $x_{i 1}$ ) is sufficient to account for the variation in the offsets and there is no significant gain in including the second independent variable (the $\delta^{13} \mathrm{C}$ value, $x_{i 2}$ ) in the regression analysis. The regression model (Figure 3) then reduces to:

$$
y_{i}=\beta_{0}+\beta_{1} x_{i 1}+\varepsilon_{i}
$$

It is convenient to calculate a derived quantity $b$, which is given by:

$$
b=-\beta_{0} / \beta_{1}
$$

This gives the mean values of $x_{i 1}\left(\delta^{15} \mathrm{~N}\right)$ for which we expect a zero offset in the ${ }^{14} \mathrm{C}$ value. In other words, $b$ is the $\delta^{15} \mathrm{~N}$ value we would expect for a human with no input to their diet from aquatic sources.

\section{BAYESIAN MODEL}

The Bayesian model that we propose follows the same logic as the linear regression. However, where it is potentially more powerful is that it can, in principle, be applied in cases where direct information on the offsets $y_{i}$ in the ${ }^{14} \mathrm{C}$ dates is lacking. Here, we use a single dependent variable model, but with enough data it would be possible to extend this to two or more variables.

We define one independent global parameter for the model $\left(\beta_{1}\right)$, which is the change in offset for a shift of one in $\delta^{15} \mathrm{~N}$ value. The model (Figure 3) for the offsets becomes:

$$
y_{i}=\beta_{1} x_{i 1}+z_{i}
$$

We assume a uniform prior for $y_{i}$ for the $n$ skeletons, which from our knowledge of this particular basin is taken to be anywhere from 0 to $1000{ }^{14} \mathrm{C} \mathrm{yr}$ (Nomokova et al. 2013). Note that this parameter is not allowed to be negative, as there should not be ${ }^{14} \mathrm{C}$ enrichment due to reservoir effects. The prior for $\beta_{1}$ is also uniform but for operational reasons constrained between 25 and $150 \mathrm{yr}$; these arbitrary end points are taken to be wide enough not to constrain the posterior (in such cases it may be useful to run models with different limits and choose ones that are wide enough not to constrain the posterior, but narrow enough to ensure fast model convergence); we choose to formally exclude zero in this case for reasons discussed below. The $x_{i 1}$ values are known. This leaves the parameters $z_{i}$ : these are assumed to be drawn from a normal distribution with a mean $\mu$ and standard deviation $\sigma$ both with uniform priors. Thus, overall we have

$$
\begin{gathered}
\beta_{1} \sim \mathrm{U}(25,150) \\
y_{i} \sim \mathrm{U}(0,1000) \\
z_{i} \sim \mathrm{N}\left(\mu, \sigma^{2}\right) \\
\mu, \sigma \sim \text { Uniform prior }
\end{gathered}
$$

When compared to the linear regression model, we can see that $\beta_{1}$ still has the same meaning, and should be directly comparable; $\mu$ is equivalent to $\beta_{0}$; $\sigma$ is equivalent to the overdispersion in $\varepsilon_{i}$. In all cases of these parameters, the Bayesian model produces a marginal posterior probability distribution rather than a point estimate. There are also other rather minor differences: for example, the prior for $y_{i}$ is not allowed to go below zero- a constraint not applied in the linear regression model. 
As for the linear regression model, we can calculate a derived quantity $b$, which is given by

$$
b=-\mu / \beta_{1}
$$

This gives us the $\delta^{15} \mathrm{~N}$ value we would expect for a human with no input to their diet from aquatic sources. Note that this value will be indeterminate if $\beta_{1}$ is zero, which is why the prior for this excludes that value.

Up to this stage, the Bayesian model assumes nothing about the relationship between different samples in the model. That is, the parameters $y_{i}$ can be left unconstrained except by their prior. In this particular case, we will want to define that the animal bones associated with the burials are assumed to be the same age as the human bones. However, the approach used here could be applied much more widely to cases where the animal bones and human bones were, for example, just within the same sedimentary sequence. Here, we choose to apply it in a case where direct comparison with the linear regression model is possible.

\section{IMPLEMENTATION OF THE MODEL IN OXCAL}

This model can be conveniently implemented within OxCal (v 4.2.3) using the chronological query language (Bronk Ramsey 2009) with calibration against IntCal09 (Reimer et al. 2009). First, we set up the global $\beta_{1}$ parameter within the overall model:

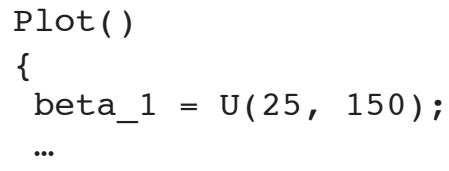

Then, for each pair of samples we calibrate the animal bone (with no offset) and the human bone. For example, for the first sample we have

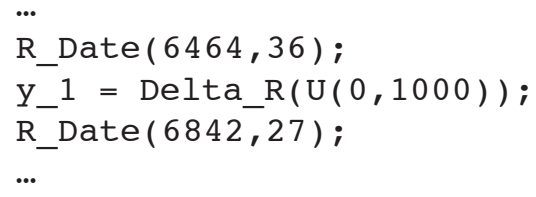

with the offset for the first sample defined as being $y_{i}$ with a uniform prior as defined above. We can then set up the parameters $z_{i}$ and ensure that these are drawn from a Normal distribution. To do this, we put the parameters within a Gaussian phase model:

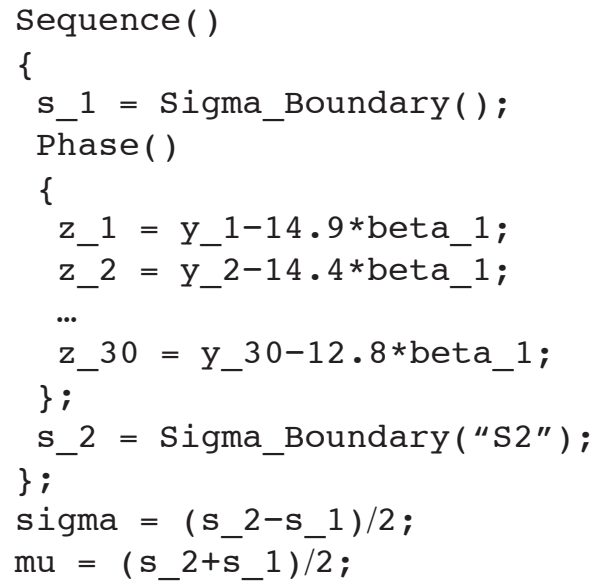


Next, we can calculate from the mean the parameter $b$ that provides an estimate for the $\delta^{15} \mathrm{~N}$ of a terrestrial-feeding human:

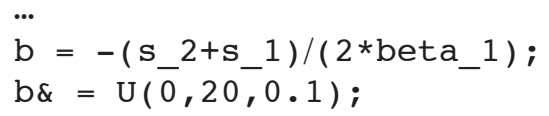

The second line here does not in practice constrain $b$, but it ensures that the output probability distribution function is reported with a resolution of 0.1 . Finally, for this particular model we wish to ensure that the human and animal bones are assumed to be of the same age. This can be done using the Combine statement wherever we have a pair of samples. More specifically, for the first pair we have

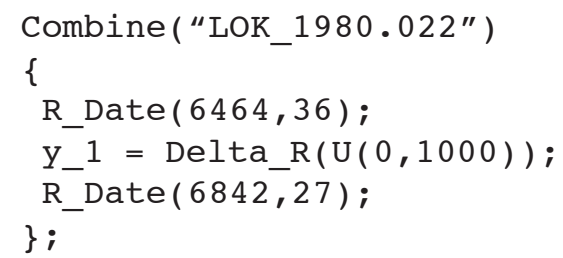

The full model is given in the online supplementary information.

\section{RESULTS}

We have applied both the linear regression analysis and Bayesian model to the full data set as well as to the data set without the two outliers (data points 9 and 10) identified above. The results of the four different models are shown in Table 2 . The linear regression analysis provides single point estimates for the main parameters of interest, whereas the Bayesian analysis provides a probability distribution function for the parameters. In most cases, the outputs are approximately normally distributed. However, this is not the case for $b$, which has a skewed distribution (see Figure 4).

Table 2 The parameters derived from the linear regression and Bayesian models of the same data sets. In each case, Model 1 includes all of the data and Model 2 excludes the two outliers. Most of the parameters are explained in the text. For the linear regression model, the $R^{2}$ and adjusted $R^{2}$ values are the coefficients of determination giving some measure of significance of the fit and, in this case, indicating that for Model 1 with all the data about $43 \%$ of the variation is explained by the dependency on $\delta^{15} \mathrm{~N}$ and $70 \%$ when two outliers are removed. The $S$ value is the standard deviation of the residuals. For parameters from the Bayesian model, we quote both a mean and standard deviation derived from the marginal posterior density functions.

\begin{tabular}{lccllcc}
\hline & \multicolumn{3}{c}{ Linear regression models } & & \multicolumn{3}{c}{ Bayesian models } \\
\cline { 7 - 8 } Parameter & Model 1 & Model 2 & & Parameter & Model 1 & Model 2 \\
\hline$n$ & 30 & 28 & & $n$ & 30 & 28 \\
$R^{2}$ & 0.453 & 0.711 & & & \\
Adjusted $R^{2}$ & 0.434 & 0.700 & & & & \\
$\beta_{0}$ & -700 & -788 & & $\mu$ & $-662 \pm 188$ & $-775 \pm 127$ \\
$\beta_{1}$ & 72.1 & 80.8 & & $\beta_{1}$ & $69.9 \pm 13.7$ & $79.6 \pm 9.3$ \\
$b$ & 9.71 & 9.75 & & $b$ & $9.26 \pm 1.00$ & $9.66 \pm 0.52$ \\
$S$ & 122 & 80.4 & & $\sigma$ & $105 \pm 18$ & $57.5 \pm 16.6$ \\
\hline
\end{tabular}




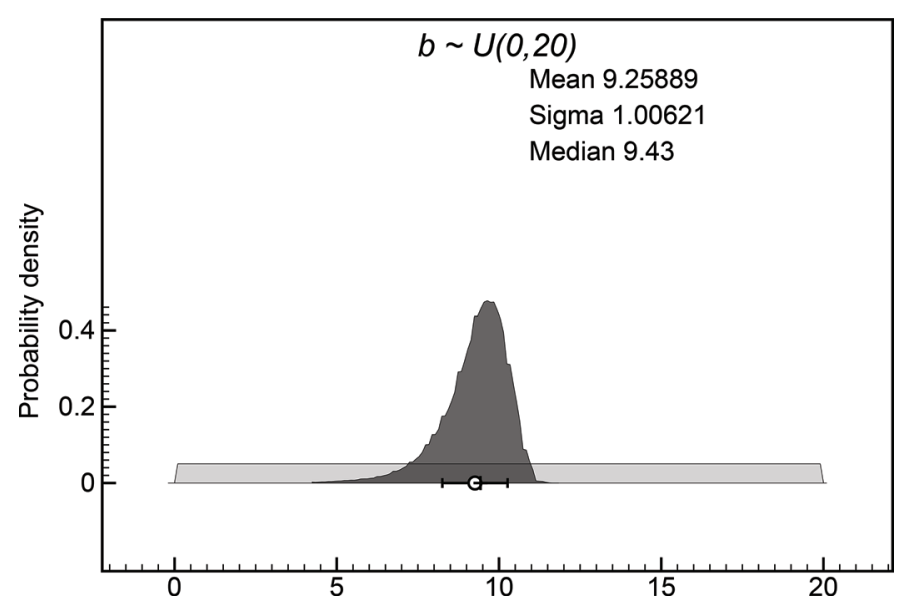

Figure 4 Graph of the Bayesian Model 1 (all data) estimate of parameter $b$, which is the $\delta^{15} \mathrm{~N}$ we would expect for a human getting all of their food from purely terrestrial sources. Note that unlike many of the other parameters, with this model the marginal posterior density distribution for this parameter is skewed and not so well described by the mean and standard deviation.

The outputs from the two different approaches are very similar. Note that the underlying assumptions are not identical and so we would not expect the results to be identical. In particular, in the Bayesian model, the offset is constrained not to be less than zero, and the parameter $\sigma$ measures the overdispersion of the data, whereas in the simple linear regression the $S$ value is the standard deviation of the residuals. However, given that the average uncertainty in the offsets is only about $43 \mathrm{yr}$, $S$ is mostly accounted for by overdispersion. We did also try a linear regression that also included variation with respect to $\delta^{13} \mathrm{C}$ but, for Model 2, for example, this only increased adjusted $R^{2}$ from 0.700 to 0.702 and decreased $S$ from 80.4 to 80.1 . This shows that adding a second variable to this model does not improve it significantly $(p=0.288)$.

With the linear regression analysis, the offsets derived could be used to correct the ${ }^{14} \mathrm{C}$ dates prior to calibration, and the scatter on the residuals added to the ${ }^{14} \mathrm{C}$ date uncertainties (in quadrature) to account for the extra noise seen in the data, which is not accounted for by the variation in stable isotopes. For the Bayesian analysis, there are three different approaches that could be taken. First, one could leave the parameterization of the model as it is but include all human samples where there is no direct information on the ${ }^{14} \mathrm{C}$ offset; this would allow the constrained data to inform the model more generally. Second, one could use the posteriors from this model as priors for a model with other human samples that one would expect to follow the same pattern, but for which we have no direct constraining information. Finally, one could use the central parameter estimates in the same way as one would for the linear regression model.

\section{CONCLUSIONS}

Bayesian modeling provides an alternative approach to dealing with offsets that are dependent on some observed variable such as $\delta^{15} \mathrm{~N}$ or $\delta^{13} \mathrm{C}$. Where we have the means to measure the offsets directly, as is the case here with the burials from Cis-Baikal, either method provides essentially similar results. The linear regression has the advantage of simplicity and that it generates diagnostic measures ( $R^{2}$ and adjusted $R^{2}$ values). However, in cases where the offset cannot be directly measured, the Bayesian approach provides the methodology needed to include the offset analysis within a larger chronological Bayesian analysis. 
Being able to build these ${ }^{14} \mathrm{C}$ offsets directly into Bayesian chronological models allows us to make quantitative use of this information, and thus to improve their accuracy. Such improved accuracy is of particular importance in the Cis-Baikal region where the human dates play such an important role in understanding the history of the local cultures. This and the forthcoming study by Schulting et al. (2014) mark only the beginning of untangling this very complicated matter.

\section{ACKNOWLEDGMENTS}

This research was conducted for the Baikal-Hokkaido Archaeology Project funded as a Major Collaborative Research Initiative (MCRI) program of the Social Sciences and Humanities Research Council of Canada. We also acknowledge support for the Oxford Radiocarbon Accelerator Unit from the Natural Environment Research Council (UK) as part of the NERC Radiocarbon Facility.

\section{REFERENCES}

Ascough P, Church MJ, Cook GT, Dunbar E, Gestsdóttir H, McGovern TH, Dugmore AJ, Friðriksson A, Edwards KJ. 2012. Radiocarbon reservoir effects in human bone collagen from northern Iceland. Journal of Archaeological Science 39(7):2261-71.

Bronk Ramsey C. 2009. Bayesian analysis of radiocarbon dates. Radiocarbon 51(1):337-60.

Cook GT, Bonsall C, Hedges REM, McSweeney K, Boroneant V, Pettitt PB. 2001. A freshwater diet-derived ${ }^{14} \mathrm{C}$ reservoir effect at the stone age sites in the Iron Gate Gorge. Radiocarbon 43(2A):453-60.

Dewar G, Pfeiffer S. 2010. Approaches to estimating marine protein in human collagen for radiocarbon date calibration. Radiocarbon 52(4):1611-25.

Katzenberg MA, Weber A. 1999. Stable isotope ecology and palaeodiet in the Lake Baikal region of Siberia. Journal of Archaeological Science 26(6):651-9.

Katzenberg MA, Goriunova OI, Weber A. 2009. Paleodiet reconstruction of Bronze Age Siberians from the mortuary site of Khuzhir-Nuge XIV, Lake Baikal. Journal of Archaeological Science 36(3):663-74.

Katzenberg MA, Bazaliiskii VI, Goriunova OI, Savel'ev N, Weber AW. 2010. Diet reconstruction of prehistoric hunter-gatherers in the Lake Baikal region. In: Weber AW, Katzenberg MA, Schurr TG, editors. Prehistoric Hunter-Gatherers of the Baikal Region, Siberia. Philadelphia: University of Pennsylvania Press. p 175-91.

Kiyashko SI, Richard P, Chandler T, Kozlova TA, Williams DF. 1998. Stable carbon isotope ratios differentiate autotrophs supporting animal diversity in Lake Baikal. Comptes Rendus Biologies 321(6):509-16.

Lanting JN, van der Plicht J. 1998. Reservoir effects and apparent ${ }^{14} \mathrm{C}$-ages. The Journal of Irish Archaeology IX:151-65

Mamonova NN, Sulerzhitskii LD. 1989. Opyt datirovaniia po C14 pogrebenii Pribaikal'ia epokhi golotsena [An attempt to C14-date some Holocene burials in the Baikal region]. Sovetskaia Arkheologiia 1:19-32. In Russian.

Minagawa M, Wada E. 1984. Stepwise enrichment of ${ }^{15} \mathrm{~N}$ along food chains: further evidence and the relation between $\delta^{15} \mathrm{~N}$ and animal age. Geochimica et Cosmochimica Acta 48(5):1135-40.
Naito YI, Honch NV, Chikaraishi Y, Ohkouchi N, Yoneda M. 2010. Quantitative evaluation of marine protein contribution in ancient diets based on nitrogen isotope ratios of individual amino acids in bone collagen: an investigation at the Kitakogane Jomon site. American Journal of Physical Anthropology 143:31-40.

Nomokonova T, Losey RJ, Goriunova OI, Weber AW. 2013. A freshwater old carbon offset in Lake Baikal, Siberia and problems with the radiocarbon dating of archaeological sediments: evidence from the Sagan-Zaba II site. Quaternary International 290-291:110-25.

Olsen J, Heinemejer J, Lübcke H, Lüth F, Terberger T. 2010. Dietary habits and freshwater reservoir effects in bones from a Neolithic NE German cemetery. $R a$ diocarbon 52(2):635-44.

Reimer PJ, Baillie MGL, Bard E, Bayliss A, Beck JW, Blackwell PG, Bronk Ramsey C, Buck CE, Burr GS, Edwards RL, Friedrich M, Grootes PM, Guilderson TP, Hajdas I, Heaton TJ, Hogg AG, Hughen KA, Kaiser KF, Kromer B, McCormac FG, Manning SW, Reimer RW, Richards DA, Southon JR, Talamo $S$, Turney CSM, van der Plicht J, Weyhenmeyer CE. 2009. IntCal09 and Marine09 radiocarbon age calibration curves, $0-50,000$ years cal BP. Radiocarbon 51(4):1111-50.

Schulting R, Bronk Ramsey C, Bazaliiskii VI, Goriunova OI, Weber A. 2014. Freshwater reservoir offsets investigated through paired human-faunal ${ }^{14} \mathrm{C}$ dating and stable carbon and nitrogen isotope analysis at Lake Baikal, Siberia. Radiocarbon.

Shishlina NI, van der Plicht J, Hedges REM, Zazovskaya EP, Sevastyanov VS, Chichagova OA. 2007. The Catacomb cultures of the north-west Caspian steppe: ${ }^{14} \mathrm{C}$ chronology, reservoir effect, and paleodiet. $\mathrm{Ra}$ diocarbon 49(2):713-26.

Shishlina NI, Zazovskaya EP, van der Plicht J, Hedges REM, Sevastyanov VS, Chichagova OA. 2009. Paleoecology, subsistence, and ${ }^{14} \mathrm{C}$ chronology of the Eurasian Caspian steppe Bronze Age. Radiocarbon 51(2):481-99.

Shishlina NI, Zazovskaya EP, van der Plicht H, Sevastyanov VS. 2012. Isotopes, plants, and reservoir 
effects: case study from the Caspian steppe Bronze Age. Radiocarbon 54(3-4):749-60.

Stuiver M, Braziunas TF. 1998. Anthropogenic and solar components of hemispheric ${ }^{14} \mathrm{C}$. Geophysical Research Letters 25(3):329-32.

Waters-Rist AL, Bazaliiski VI, Weber A, Katzenberg MA. 2011. Infant and child diet in Neolithic hunter-fisher-gatherers from Cis-Baikal, Siberia: intra-long bone stable nitrogen and carbon isotope ratios. American Journal of Physical Anthropology 146(2):225-41.

Weber A. 1995. The Neolithic and Early Bronze Age of the Lake Baikal region, Siberia: a review of recent research. Journal of World Prehistory 9(1):99-165.

Weber AW, Goriunova OI. 2011. Hunter-gatherer migrations, mobility and social relations: a case study from the Bronze Age Baikal region, Siberia. In Weber AW, Zvelebil M, editors. Human bioarchaeology: group identity and individual life histories. Journal of Anthropological Archaeology 30:523-48.

Weber AW, Link DW, Katzenberg MA. 2002. Hunter-gatherer culture change and continuity in the Middle Holocene of the Cis-Baikal, Siberia. Journal of Anthropological Archaeology 21(2):230-99.

Weber A, McKenzie H, Beukens RP, Goriunova OI
2005. Evaluation of radiocarbon dates from the Middle Holocene hunter-gatherer cemetery Khuzhir-Nuge XIV, Lake Baikal, Siberia. Journal of Archaeological Science 32(10):481-500.

Weber AW, Beukens R, Bazaliiskii VI, Goriunova OI, Savel'ev NA. 2006. Radiocarbon dates from Neolithic and Bronze Age hunter-gatherer cemeteries in the Cis-Baikal region of Siberia. Radiocarbon 48(3): $1-40$.

Weber AW, McKenzie H, Beukens R. 2010. Radiocarbon dating of Middle Holocene cultural history in Cis-Baikal. In: Weber AW, Katzenberg MA, Schurr TG, editors. Prehistoric Hunter-Gatherers of the Baikal Region, Siberia. Philadelphia: University of Pennsylvania Press. p 27-49.

Weber AW, White D, Bazaliiskii VI, Goriunova OI, Savel'ev NA, Katzenberg MA. 2011. Hunter-gatherer foraging ranges, migrations, and travel in the middle Holocene Baikal region of Siberia: insights from carbon and nitrogen stable isotope signatures. Journal of Anthropological Archaeology 30(4):523-48.

Wood RE, Higham T, Buzilhova A, Surorov A, Heinemeier J, Olsen J. 2013. Freshwater radiocarbon reservoir effects at the burial ground of Minino, northwest Russia. Radiocarbon 55(1):163-77. 